\title{
Management of HCV-Related Liver Disease in Hemophilia and Thalassemia
}

\author{
Maria Grazia Rumi, MD ${ }^{1}$ Vito Di Marco, MD ${ }^{2}$ Massimo Colombo, MD \\ ${ }^{1}$ Hepatology Unit,Ospedale San Giuseppe and University of Milan, \\ Milan, Italy \\ ${ }^{2}$ Gastroenterology and Hepatology Unit, Azienda Universitaria \\ Ospedaliera Policlinico and University of Palermo, Palermo, Italy \\ ${ }^{3}$ Department of Medicine, Clinical and Research Center, Humanitas \\ Hospital, Rozzano, Italy

\begin{abstract}
Address for correspondence Massimo Colombo, MD, Department of Medicine, Clinical and Research Center, Humanitas Hospital, via Manzoni 56, 20089 Rozzano, Italy (e-mail: mcolombo46@yahoo.it; massimo.colombo@humanitas.it). Mariagrazia Rumi, MD, Hepatology Unit, Ospedale San Giuseppe and University of Milan, via San Vittore 12, Milan 20122, Italy
\end{abstract} \\ (e-mail: mariagrazia.rumi@unimi.it).
}

Semin Liver Dis 2018;38:112-120.

\begin{abstract}
\section{Keywords}

- hepatitis C

- hemophilia

- sickle cell anemia

- thalassemia

- direct antiviral agents

Chronic infection with the hepatitis $\mathrm{C}$ virus (HCV) has long been the dominant complication of substitution therapy in patients with inherited blood disorders and the cause of anticipated death due to end-stage liver disease. In hemophilia, transmission of HCV with clotting factors concentrates started to be curbed in the mid-1980s following the adoption of procedures of virus inactivation of concentrates based on heat, whereas in the 1990s treatment of HCV infection with interferon monotherapy was attempted, however, with little success. The advent of combination therapy of interferon with ribavirin led to a substantial improvement of treatment outcome (40\% rate of cure), that however was still of limited efficacy in patients with advanced liver disease, those with high load of HCV genotype 1, and patients coinfected with the human immunodeficiency virus. In this latter population, while the course of hepatitis $C$ was accelerated as a consequence of immunodeficiency, the advent of highly active antiretroviral therapy led acquired immunodeficiency syndrome (AIDS) to decline and hepatitis $C$ to progressively emerge as a dominant cause of mortality, in parallel. In patients with thalassemia, transfusion-related transmission of HCV was efficiently interrupted in 1992 with the advent of sensitive screening tests for testing donors for $\mathrm{HCV}$, whereas treatment with interferon and ribavirin of infected thalassemics was constrained by an increased risk of anemia due to the hemolytic properties of ribavirin coupled with interferon-induced bone marrow suppression. The advent of safe and potent regimens based on the oral administration of direct antiviral agents has revolutionized therapy of $\mathrm{HCV}$ in patients with congenital blood diseases, providing substantial clinical benefits and making elimination of infection in these populations, possible.
\end{abstract}

Patients with inherited blood disorders (IBDs) like those with hemophilia, sickle cell anemia, and thalassemia, have long been exposed to the risk of acquiring blood borne infections before adequate procedures for screening of donated blood and manufacturing of virus-inactivated clotting factors preparations were widely applied. ${ }^{1,2}$ Consequently, adult patients with IBD are those with highest rates of infection with the hepatitis $C$ virus ( $\mathrm{HCV}$ ), a complication that contributed to deteriorate the clinical status of many patients who had long been exposed to an increased risk of end-stage liver disease including hepatocellular carcinoma (HCC). ${ }^{3-6}$ In the very unfortunate subset of patients who acquired
Copyright @ 2018 by Thieme Medical Publishers, Inc., 333 Seventh Avenue, New York, NY 10001, USA. Tel: +1(212) 584-4662. ISSN $0272-8087$. 
transfusion-associated coinfection with the human immunodeficiency virus (HIV), the course of hepatitis $C$ has been accelerated, in many cases precluding optimal adherence to antiretroviral therapy, with deleterious consequences on the course of HIV infection, as well. ${ }^{7,8}$ Less is known on the course of hepatitis $C$ in hemolytic disorders, where the prevalence of HCV among persons with sickle cell anemia and thalassemia (20-35\%) varies widely. ${ }^{9}$ In this special population, transfusion transmitted HCV infection was the dominant cause of liver disease before sensitive screening tests for HCV had become available, whereas the risk of progressive liver disease is confounded by secondary iron overload.

In the last two decades, the threat of transmission of $\mathrm{HCV}$ (and HIV) with clotting factor preparations has progressively dissolved following the advent of effective procedures for manufacturing virus-free clotting factors coupled with the implementation of screening for HCV of blood obtained from both repeat volunteers and payed donors. More recently, virus safety of replacement therapy has been implemented by the availability of recombinant factors, leading to a majority of the new generations of IBD patients to run a HCV-free life. ${ }^{10-12}$ This is not a trivial point considering the death toll payed by IBD patients before the advent of direct antiviral agents (DAAs), when the only hope for a cure of chronic HCV infection rested on the administration of interferon (IFN) associated to ribavirin (RBV), i.e., a poorly tolerated regimen that was difficult to apply in patients with anemia and endowed with limited antiviral efficacy. ${ }^{13,14}$ The advent of safe, potent, and user-friendly DAAs to treat HCV has resulted in the dawn of a new era for adults with IBD, making the elimination of HCV in this special population, possible.

\section{The Burden of Hepatitis $\mathbf{C}$ in Hemophilia}

Starting in the 1970s, the hemophilia community was hit by an epidemic of transfusion-associated hepatitis $C$ (in those times termed non-A, non-B hepatitis) as refinements in management and prevention of bleeding complications led to an increased demand of substitution therapy with clotting factors, that could only be satisfied by expanding the access to highly infectious concentrates manufactured from large plasma pools obtained from payed donors. ${ }^{1,2}$ One or two decades later, between 50 and $80 \%$ of multitransfused hemophiliacs resulted to be chronically infected with HCV (HCV ribonucleic acid [RNA] seropositive), whereas only a tiny minority of anti-HCV seropositive patients testing repeatedly HCV RNA seronegative had had a spontaneous recovery from an acute episode of transfusion-transmitted hepatitis C. ${ }^{1,2}$ While the frequency of chronic HCV infection appeared to be linearly correlated with the severity of the clotting factor defect and hence with the intensity of the transfusion history, the course of the infection began to be delineated following the identification of a worse outcome of patients with a longer history of infection, those with HIV coinfection (present in $25 \%$ of the population) and those with environmental or life-style predictors of adverse outcome, alcohol abuse, and metabolic syndrome above all. ${ }^{7,8,15}$ Interestingly enough, multitransfused hemophiliacs were among the first HCV populations in whom occult infection with the hepatitis B virus (HBV) (seropositivity for HBV deoxyribonucleic acid [DNA] in HBsAg seronegative patients) was recognized using molecular approaches, a condition that was later associated with a worse outcome of hepatitis $\mathrm{C}$ in ordinary patients. ${ }^{16}$

Not unexpectedly, hepatitis $C$ in hemophilia was frequently associated with the hard-to-cure subtype "a" of the genotype 1 of HCV transmitted with clotting factors manufactured from plasma of payed donors, particularly from the United States, including individuals with risky behaviors.

In those same years, the importance of HCV as a cause of death in hemophilia was clearly recognized. The finding that HCV caused accelerated progression of HIV disease while antiretroviral therapy was constrained in patients with liver failure, led HCV to stand as an independent predictor of worse prognosis in HIV-infected hemophiliacs. ${ }^{8,15,17}$ The dramatic decrease of HIV-related morbidity and mortality allowed also to recognize that the progression of liver disease was accelerated in the presence of HIV in parallel with increased HCV load. Prospective studies revealed sharp differences in the prognosis of hepatitis $C$ in relation to HIV seropositivity: in one study, the 16-year cumulative incidence of end-stage $\mathrm{HCV}$ among those with and without HIV was 14 and $2.6 \%$, respectively, whereas in more than one study, HCC started to surface as a dominant complication of long-standing infection with HCV. ${ }^{18,19}$ In a questionnairebased survey of 11,801 hemophilic patients from 30 centers from U.S. and 24 from U.K., 10 patients with HCC were identified, all with cirrhosis and a majority infected with HCV. ${ }^{19}$ In two studies in Italy, the prevalence of HCC was found to greatly exceed that expected in the general population ( 360 vs. $7 \times 100,000$ individuals) and to be more frequently clinically aggressive than in ordinary HCV patients. $^{20,21}$ Treatment of liver failure and HCC with liver transplantation was successfully performed in several HCVinfected hemophiliacs, resulting in global survival benefits and a cure of the underlying clotting factor defect. ${ }^{22}$ However, even if the bleeding risk of hemophilia did not influence both listing to and outcome of liver transplantation compared with nonhemophilic populations, the number of hemophilic candidates to liver transplant has remained limited, mainly because most hemophilic patients were burdened by comorbidities which limit listing. The outcome of liver transplantations performed for end-stage HCV, however, greatly benefitted from the arrival of second-generation DAAs, which made prevention of recurrent hepatitis $\mathrm{C}$, a relevant cause of shortened survival of liver transplanted patients, possible and associated to significant survival benefits. $^{23}$

\section{Prevention and Therapy of Hepatitis $C$ in Hemophilia}

Replacement therapy of hemophilia started in the late 1940s with the infusion of fresh-frozen plasma to be replaced in the 
mid-1960s by cryoprecipitates pooled from a few to a maximum of 20 donors. The risk of transmitting blood borne viruses sky rocketed in the early 1970s following the widespread use of concentrates derived from large pools of plasma obtained from 20,000 to 50,000 donors. ${ }^{1,2}$ In the mid-1980s, the epidemic of HIV spread by contaminated factor concentrates caused acceleration in the production of factors sterilized with virucidal procedures, an approach that had previously been deferred not to compromise the manufacturing yield and hence patients' access to replacement therapy. Development of safe and effective procedures of virus inactivation based on physical (dry and vapor heat, ultraviolet [UV] light) and chemical (organic solvent and detergent approaches), led in the mid-1980s to the marketing of safer factor concentrates that contributed to prevent transmission of enveloped viruses, unfortunately not of the naked ones. ${ }^{11,24}$ The risk of transmission of naked viruses with inactivated concentrates was testified by an outbreak of hepatitis A virus (HAV) infection occurring among patients infused with solvent-/detergent-treated factors that led to promote HAV vaccination as a standard of care in hemophilia, too. ${ }^{25}$ More recently, the advent of recombinant factors has further contributed to protect the hemophilia community against the risk of transfusion-associated transmission of blood borne viruses, including HCV.

Antiviral treatment of HCV-infected hemophiliacs was first attempted since the early 1990s, however, with little success. The reason for this was the combined effect of IFN monotherapy being the only, yet suboptimal, therapeutic regimen available to treat HCV and the prevalence of hemophiliacs having such adverse predictors of treatment outcome as the genotype 1 of HCV, high viral load, advanced fibrosis, and HIV coinfection. With all these premises, the selection process to identify hemophilic patients eligible for treatment included only those with persistently elevated transaminases, well compensated liver disease, and commitment to antiviral treatment. In the first study of therapy, 16 patients were subcutaneously dosed with 3 million units (MU) of IFN monotherapy administered three times a week for 6 or 12 months, ${ }^{26}$ where however treatment response could only be assessed combining assessment of serum transaminases with histological evaluation. Although only four patients reached a sustained biochemical response, i.e., normal values of transaminases, accompanied by improvement of liver inflammation at histology, the study opened the way to a series of investigations that evaluated the efficacy of different doses of IFN (between 3 and $6 \mathrm{MU}$ ) or of an induction dose of $9 \mathrm{MU}$ in regimens administered for 6 or 12 months. ${ }^{27-39}$ In general, the sample size of those studies was small enrolling accurately selected patients. Two studies only enrolled more than 50 patients, the majority of whom were HIV seronegative and without relevant comorbidities, i.e., not fully representative of real-life patients. Using the more appropriate endpoint of HCV eradication (sustained virological response, SVR), the outcome of antiviral therapy turned out to be disappointingly poor, as the cure rates ranged between $0 \%$ and less than $15 \%$, only. The only exception was a study in Japan reporting $47 \%$ rate of cure, $^{31}$ a success rate, however, that was inflated by the administration of high doses of IFN and enrolment of patients infected with easy-to-cure genotype 2 or 3 of $\mathrm{HCV}$. Not surprisingly, major reasons accounting for the suboptimal rates of virological response of hemophiliacs to IFN were the prevalence of high viral load, impaired immune competence due to repeated exposure to allogenic serum proteins, accumulation of HCV quasi-species as a result of multiple infusions with infected concentrates, long duration of infection, and high prevalence of genotype 1, all well identified negative predictors of treatment outcome in nonhemophilic populations. ${ }^{15}$ In hemophilia, IFN refractoriness has also been associated to a change of HCV genotype during therapy, as it may result from infection with different clones transmitted by multiple infusions of infected concentrates that had different sensitivity to IFN. ${ }^{32}$ Coinfection with HIV long standed as a dominant negative predictor of IFN response too, as indicated by studies of monotherapy where only $8 \%$ of HIV coinfected patients ultimately achieved virus eradication. ${ }^{14}$ The response rates could significantly be improved following the combined administration of the nucleoside analog RBV in both HIV positive and HIV negative hemophiliacs, including previously nonresponders to IFN monotherapy. ${ }^{40-43}$ In treatment naive populations, a cure of the infection was in fact attained in $40 \%$ of the patients, matching exactly the outcome of IFN therapy of nonhemophilic populations. While in two studies of retreatment of nonresponders to IFN monotherapy, one-third of all treated patients achieved a cure from HCV infection, ${ }^{44,45}$ the rates of SVR were further optimized following the advent of pegylated (Peg) IFN. This regimen combined with RBV led to achieve $50 \%$ rates of SVR in the difficult-to-cure patients infected with HCV genotype 1 and 4 , and to more than $80 \%$ in the fewer, but easier-to-cure patients with HCV genotype 2 and $3 .{ }^{46,47}$ The downside of this regimen, however, was the $10 \%$ of patients who required dose reduction of either drug due to the onset of significant symptoms or complications like anemia and neutropenia. As these adverse events occurred more frequently in patients with advanced liver fibrosis compared with hemophiliacs with milder liver disease, this led to emphasize the recommendation for early treatment of all-treatment naive patients lacking specific or generic contraindications. ${ }^{48}$ Owing to the fact that the progression of liver disease is accelerated in patients with HIV coinfection, treatment guidelines endorsed by National Institutes of Health (NIH), American Association for the Study of Liver Diseases (AASLD), and the European Consensus Conference in Paris, 2005, recommended 48 weeks of Peg IFN/RBV therapy in HIV coinfected patients, irrespective of genotype, whenever the risk of serious liver disease was judged to outweigh the risk of morbidity due to adverse effects of therapy. ${ }^{49-51}$

In 2013, the therapeutic scenario of HCV was revolutionized by the advent of safe and potent all-oral IFN-free therapies, making the elimination of hepatitis $C$ in hemophilia a realistic goal. ${ }^{52,53}$ The first report in hemophilia concerned a 24-week course of the NS5B polymerase inhibitor sofosbuvir associated to the NS5A inhibitor daclatasvir 
Table 1 DAA treatment of HCV-infected patients with hemophilia or von Willebrand disease ${ }^{55-59}$

\begin{tabular}{|l|l|l|l|l|l|l|l|}
\hline Author, y & Patients & $\begin{array}{l}\text { HIV- } \\
\text { coinfected } \\
(\%)\end{array}$ & $\begin{array}{l}\text { Patients } \\
\text { with } \\
\text { cirrhosis }\end{array}$ & Genotypes & DAA regimen & Overall SVR & $\begin{array}{l}\text { SVR in HIV- } \\
\text { coinfected }\end{array}$ \\
\hline Stedman et al, 2015 & 14 & $0 / 14$ & 1 & $1 \mathrm{a}, 1 \mathrm{~b}$ & SOF/LDV + RBV & $14 / 14(100 \%)$ & - \\
\hline Walsh et al, 2017 & 120 & $26 / 120(22)$ & 37 & $1 \mathrm{a}, 1 \mathrm{~b}, 2,4$ & $\begin{array}{l}\text { SOF + RBV } \\
\text { SOF/LDV }\end{array}$ & $118 / 120(99 \%)$ & $\begin{array}{l}25-26 / 26 \\
(96-100 \%)\end{array}$ \\
\hline $\begin{array}{l}\text { Nagao and Hanabusa, } \\
2017\end{array}$ & 43 & $20 / 43(47)$ & 9 & $1 \mathrm{a}, 1 \mathrm{~b}, 4$ & SOF/LDV & $41 / 43(95 \%)$ & $18 / 20(90 \%)$ \\
\hline $\begin{array}{l}\text { Lee et al, 2017 } \\
\text { Hézode et al, } 2017\end{array}$ & 47 & $0 / 30$ & 4 & $1 \mathrm{a}, 1 \mathrm{~b}, 2$ & $\begin{array}{l}\text { SOF/LDV, DCV + } \\
\text { ASV SOF + RBV }\end{array}$ & $28 / 30(93 \%)$ & - \\
\hline
\end{tabular}

Abbreviations: ASV, asunaprevir; DAA, direct antiviral agent; DCV, daclatasvir; EBV, elbasvir; GZR, grazoprevir; HCV, hepatitis C virus; HIV, human immunodeficiency virus; LDV, ledipasvir; n.d., not done; RBV, ribavirin; SOF, sofosbuvir; SVR, sustained virological response.

to treat two HIV coinfected, treatment experienced hemophiliacs with end-stage $\mathrm{HCV}^{54} \mathrm{~A}$ cure of the infection was attained by both patients, without any significant side effect, whereas HIV infection had remained suppressed following adjustment of antiretroviral therapy. In a study in the United States, 120 patients with bleeding disorders were treated with sofosbuvir associated to ledipasvir to treat genotype 1 and $4 \mathrm{HCV}$ and to RBV to treat HCV genotype 2 and 3 leading to $>95 \%$ rates of cure, irrespective of the presence of cirrhosis, prior IFN failure, or HIV coinfection. ${ }^{55}$ Similar results were obtained in 43 Japanese patients treated with the same combination therapy for 12 weeks, where the efficacy was not significantly different between HIV positive and HIV negative patients (95\% vs. $100 \%$ ), but apparently lower (7/9) in patients with cirrhosis, suggesting that the addition of RBV may be advantageous in patients with advanced liver disease. ${ }^{56}$ The success rate of sofosbuvir/ledipasvir regimen was universal in 14 patients with hemophilia or von Willebrand disease who were treated with add-on RBV, ${ }^{57}$ whereas sofosbuvir/RBV was a suboptimal therapeutic regimen in Korean patients with HCV 2a/2b where two patients experienced a viral breakthrough associated to emergence of resistant variants ${ }^{58}$ (- Table $\mathbf{1}$ ).

More recently, the combination of an NS5A inhibitor (elbasvir) and a protease inhibitor (grazoprevir) directed against genotype 1 and $4 \mathrm{HCV}$, proved to be highly effective in compensated patients including those with severe chronic kidney disease, with and without cirrhosis, prior IFN failure, and HIV coinfection. ${ }^{59}$ Among 47 patients with hemophilia or von Willebrand disease who were randomized to immediate 12 -week treatment, 42 (89\%) achieved virus eradication, the suboptimal response rate reflecting a patient with a relapse attributable to baseline NS5 RASs conferring resistance to elbasvir. These patients are considered liable to respond following the addition of RBV or by extending to 16-week treatment with elbasvir/grazoprevir. ${ }^{60}$

The recent approval of second-generation multigenotypic DAAs with increased potency, different mechanisms of action, and higher genetic barrier, might allow to treat a broad range of patients reducing the need of tailoring the regimen on the individual patient characteristics, an approach that is expected to improve algorithms of HCV therapy in hemophilia. ${ }^{61,62}$

\section{The Burden of Hepatitis $\mathbf{C}$ in Thalassemia}

Quality of life and survival of thalassemia patients living in resource-rich countries have improved significantly over the past 30 years, following implementation of HCV screening of donors and optimization of oral iron chelation regimens. ${ }^{63-66}$ In those regions, this translated in a significant reduction of the risk of transfusion-transmitted HCV infection, ${ }^{67}$ at striking variance with developing countries where standard of care approaches to obtain safe blood transfusions are not fully implemented. ${ }^{68}$ In the West, cohorts of HCV infected thalassemic patients are mainly composed by adults, $80 \%$ of whom acquired the infection before $1990,{ }^{69}$ whereas in the Middle East and Asia the same is true also for many children or young adults (10-40\% of all patients) who acquired the infection in the last decades resulting in the development of chronic liver disease ${ }^{70-77}$ (-Table 2). Not unexpectedly, thalassemia population shows a wide geographical heterogeneity in the infecting HCV genotype: the genotype 1 of $\mathrm{HCV}$ prevails in areas like Italy, whereas genotype 3 is common among patients who live in Greece, Australia, Iran, and India. Patients in Egypt and Lebanon are more frequently infected by HCV genotype 4, whereas HCV genotypes 5 and 6 infect a minority of Chinese patients, only. ${ }^{9}$ While spontaneous recovery from acute infection occurred in less than one-third of all patients, the rest inexorably proceeding toward chronic liver disease, "favorable" genotypes of IL28b (IFNL3) single-nucleotide polymorphisms (SNPs) appear to associate with control of infection in thalassemia patients favoring spontaneous clearance of HCV infection and response to IFN with less propensity to develop cirrhosis. ${ }^{78}$

While heart failure stands as a major cause of mortality in thalassemia despite the switch from subcutaneous desferrioxamine to oral chelation regimens, ${ }^{79,80}$ chronic liver disease due to HCV has long been a relevant complication of 
Table 2 Prevalence of HCV infection in thalassemia patients

\begin{tabular}{|c|c|c|c|c|c|}
\hline References & Year & Geographical area & $\begin{array}{l}\text { Screened thalassemia } \\
\text { patients (number) }\end{array}$ & $\begin{array}{l}\text { Mean age } \\
\text { (y) }\end{array}$ & $\begin{array}{l}\text { Anti-HCV } \\
\text { (\%) }\end{array}$ \\
\hline Jang et $\mathrm{al}^{70}$ & 2017 & Taiwan & 67 & 26 & 37.5 \\
\hline Ahmed Kiani et a $\mathrm{I}^{71}$ & 2016 & Pakistan & 1,253 & 10 & 21.7 \\
\hline Jafroodi et al ${ }^{72}$ & 2015 & Iran & 1,113 & 26.1 & 13.6 \\
\hline Al-Naamani et al ${ }^{73}$ & 2015 & Oman & 200 & 23.1 & 41 \\
\hline Chakrabarty et a ${ }^{74}$ & 2014 & Bangladesh & 200 & 6 & 2 \\
\hline Hussein $^{75}$ & 2014 & Egypt & 200 & 9 & 24 \\
\hline Mansour $^{76}$ & 2012 & Egypt & 200 & 13 & 40 \\
\hline Al-Sweedan et al ${ }^{77}$ & 2011 & Jordan & 122 & 14 & 32.2 \\
\hline
\end{tabular}

Abbreviation: $\mathrm{HCV}$, hepatitis $\mathrm{C}$ virus.

thalassemia care. This is the consequence of an interaction between iron overload and chronic infection with HCV that leads to progressive accumulation of fibrosis in the liver, thereby increasing the risk of end-stage liver disease. In a retrospective analysis with liver biopsies of 126 transfusiondependent patients (mean age 17 years), advanced stages of fibrosis were detected in $32 \%$ out of $68 \mathrm{HCV}$-RNA positive patients compared with only $4 \%$ out of $68 \mathrm{HCV}$-RNA negative patients, with male gender (odds ratio [OR]: 4.12) and serum HCV-RNA (OR: 11.04) being independent predictors of advanced liver fibrosis. The propensity of iron to fuel progression of hepatitis $C$ clearly emerged from a study where a minority of HCV-RNA negative patients were found to have severe fibrosis in the presence of low liver iron load compared with more patients with HCV and high liver iron overload who had advanced liver fibrosis. Another study clearly highlighted how iron overload can be toxic to the liver independently from HCV, as it showed that adequate chelation therapy was able to prevent accumulation of liver fibrosis in thalassemia patients who were unaffected by HCV. ${ }^{81}$

While liver biopsy has long been the gold standard for quantifying inflammation, fibrosis, and iron overload in the liver of patients with liver disease of any etiology including thalassemia, evaluation of liver stiffness through the noninvasive technique of transient elastography has progressively gained popularity to become nowadays a reliable predictor of liver disease severity, particularly among patients with chronic HCV infection. ${ }^{82}$ This approach, however, retains several limitations, one above all is the inability to disentangle the quotas of stiffness related to fibrosis versus those attributable to other injuries including cell necrosis and iron overload. Owing to the fact that thalassemia patients may have liver stiffness values modified independently of iron overload, combining magnetic resonance imaging (MRI) with transient elastography might offer a more reliable assessment of iron overload of the liver. ${ }^{83-85}$

In analogy with cohorts studies of ordinary patients, the prevalence of cirrhosis in thalassemia patients in the United States, Italy, and Greece ranged from 10 to $20 \%$, ${ }^{6,78,86,87}$ and not surprisingly, male sex, high HCV-RNA load, and high liver iron concentration were all significantly associated with increased risk of cirrhosis and HCC. Of note, the incidence of HCC in thalassemia patients has progressively increased over the past 10 years, mainly as a consequence of a significant improvement of patient survival coupled with a long history of HCV infection and liver iron overload, both factors being well-recognized mediators of liver carcinogenesis. $^{88}$ In a multicenter retrospective study performed in 52 Italian thalassemia centers, 22 patients were found to have a HCC, the vast majority (70\%) harboring serum HCV-RNA, however, without data on the incidence rates of HCC in this population. ${ }^{89}$ In a prospective study of surveillance with abdominal ultrasound of 108 thalassemia patients (median age 37 years, 72 with risk factors for HCC like iron overload, $\mathrm{HCV}$, hepatitis B, cirrhosis), two patients were found to develop an HCC, with an estimated annual incidence rate of $2 \% .{ }^{90}$ In a recent report from 55 centers in Italy, 60 new cases of HCC were identified among 5,855 thalassemia patients (nearly the entire burden of thalassemia in Italy) between 2002 and 2012. The cumulative incidence was $1.02 \%$ (95\% confidence interval $[\mathrm{CI}]: 0.78-1.3$ ) with 32 cases out of 4,248 patients with thalassemia major $(0.75 \%$; $95 \% \mathrm{CI}$ : $0.52-1.06)$ and 28 cases out of 1,607 patients with thalassemia intermedia (1.74\%; 95\% CI: 1.16-2.51). Forty-three patients (69\%) circulated serum HCV RNA, and 41 (66\%) died at the end of observation period, thereby confirming chronic infection with HCV to stand as a determinant of survival in thalassemia patients. ${ }^{91}$

\section{Treatment of Hepatitis $C$ in Thalassemia}

In the IFN era, thalassemia patients with chronic HCV infection were considered a "difficult-to-treat" population, because antiviral therapy was challenged by difficulties in maintaining optimal dosing of IFN and RBV, owing to worsening of anemia caused by RBV, which led to increased demand of blood transfusions and increase of iron overload. When IFN monotherapy was the only therapeutic option, the rates of cure of HCV were consistently less than $50 \%$ in all treated patients, with preference for patients with moderate liver fibrosis, low liver iron concentration, and infection with 


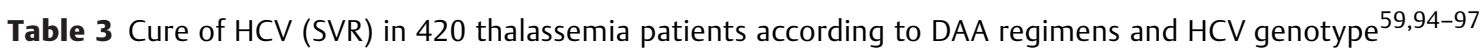

\begin{tabular}{|l|l|l|l|l|l|l|l|}
\hline DAA regimens & Patients & $\begin{array}{l}\text { HCV1a } \\
(\boldsymbol{n}=\mathbf{7 5})\end{array}$ & $\begin{array}{l}\text { HCV1b } \\
(\boldsymbol{n}=\mathbf{2 6 2})\end{array}$ & $\begin{array}{l}\text { HCV2 } \\
(\boldsymbol{n}=\mathbf{2 4})\end{array}$ & $\begin{array}{l}\text { HCV3 } \\
(\boldsymbol{n}=\mathbf{3 1})\end{array}$ & $\begin{array}{l}\text { HCV4 } \\
(\boldsymbol{n}=\mathbf{1 8})\end{array}$ & SVR \\
\hline SOF/LDV & 175 & $11 / 12$ & $152 / 156$ & & & $7 / 7$ & $170(97.1 \%)$ \\
\hline SOF/LDV + RBV & 16 & $5 / 5$ & $8 / 9$ & & & $2 / 2$ & $15(93.7 \%)$ \\
\hline SOF + DCV & 49 & $3 / 3$ & $9 / 9$ & $12 / 13$ & $19 / 20$ & $3 / 4$ & $46(93.8 \%)$ \\
\hline SOF + DCV + RBV & 12 & $1 / 1$ & & & $11 / 11$ & & $12(100 \%)$ \\
\hline OMB/PRV/r + DSV + RBV & 2 & $1 / 1$ & $1 / 1$ & & & & $2(100 \%)$ \\
\hline OMB/PRV/r + DSV & 18 & $1 / 1$ & $16 / 17$ & & & & $17(94.4 \%)$ \\
\hline SOF + SIM & 29 & $4 / 4$ & $18 / 20$ & & & $5 / 5$ & $27(93.1 \%)$ \\
\hline SOF + SIM + RBV & 2 & & $2 / 2$ & & & & $2(100 \%)$ \\
\hline GRZ + ELB & 103 & $43 / 47$ & $44 / 46$ & & & & $97(94.2 \%)$ \\
\hline SOF + RBV & 14 & $1 / 1$ & $1 / 2$ & $11 / 11$ & & & $13(92.8 \%)$ \\
\hline Overall SVR & & $70(93.3 \%)$ & $249(95 \%)$ & $23(95.8 \%)$ & $30(96.7 \%)$ & $17(94.4 \%)$ & \\
\hline
\end{tabular}

Abbreviations: DAA, direct antiviral agent; DCV, daclatasvir; DSV, dasabuvir; ELB, elbasvir; GZR, grazoprevir; HCV, hepatitis C virus; LDV, ledipasvir; OMB, ombitasvir; PRV, paritaprevir; RBV, ribavirin; SIM, simeprevir; SOF, sofosbuvir; SVR, sustained virological response.

HCV genotype $2 .^{92}$ With the advent of Peg-IFN associated to RBV and treatment tailoring according to HCV genotype, the only patients exceeding $50 \%$ rates of cure were those infected by genotype 2 of $\mathrm{HCV}(60 \%)$, in the face, however, of increased transfusion volumes needed to counteract RBV-induced anemia. ${ }^{93}$ The current European Association for the Study of the Liver (EASL) Clinical Practice Guidelines recommend IFN-free regimens for the treatment of HCV infection in patients with hemoglobinopathies, as DAAs have provided $>90 \%$ rates of cure, irrespective of HCV genotype or history of previous antiviral therapy. ${ }^{60}$ In a multicenter phase III randomized trial, 95\% (18/19) and 98\% (40/41) of patients with sickle cell disease and thalassemia, achieved a cure of hepatitis $C$ following 12-week treatment with elbasvir/grazoprevir, respectively. ${ }^{94}$ In the 6 patients with a hepatitis relapse, 4 with genotype $1 \mathrm{a}, 1$ with genotype $1 \mathrm{~b}$, and 1 with genotype 4, pretreatment NS5A and NS3 RAS were detected in all patients at time of treatment failure. Serious adverse events were reported in two patients only, one with thalassemia developing erosive gastritis and hypophosphatemia, and another one with sickle cell disease developing a hemolytic crisis. High rates of cure were confirmed by an observational multicenter study ${ }^{95}$ of 61 thalassemia patients with a mix of HCV genotypes (median age, 43 years) and advanced liver disease ( $79 \%$ with cirrhosis) who were exposed to sofosbuvir/RBV, SOF + simeprevir $\pm \mathrm{RBV}, \mathrm{SOF}+$ daclatasvir $\pm \mathrm{RBV}$, SOF + ledipasvir \pm RBV, and ombitasvir/paritaprevir-ritonavir + dasabuvir \pm RBV. The overall rates of hepatitis cure were $90 \%$, all DAA regimens were well tolerated, and no major adverse events or drug-drug interactions occurred. In a study in Italy ${ }^{95}$ with sofosbuvir/ledipasvir in 100 patients with thalassemia major and HCV genotype 1 or 4 , the cure rates were as high as $98 \%$, whereas in another observational study in Italy involving 139 patients, the rates of cure were $94 \%$, with three patients dying during the period of observation for causes unrelated to DAAs, one patient not achieving a virological response, and five (4\%) relapsing after the end of therapy. ${ }^{96}$ Interestingly, therapy with DAA was not associated with increased iron overload, whereas SVR patients showed significant reductions in ferritin values after the end of antiviral therapy.

More than 2 million people have been successfully treated with generic DAA worldwide, and those regimens proved to be as safe and effective as brand named DAA in 29 thalassemia patients, too ${ }^{97}$ (-Table 3). The effectiveness of generic DAAs was proven on a small number of thalassemia patients: a cure of hepatitis $C$ was achieved by all treated patients at the expenses of a transiently increased transfusional volume during antiviral therapy, particularly in those exposed to RBV. These findings, therefore, align with reports in millions of ordinary patients who have successfully been treated with generic DAAs, suggesting that generics are a valuable option for a cost-saving therapy of HCV in thalassemia in developing regions that cannot afford the costs of brand named antiviral therapies. ${ }^{98}$ All in all, the advent of IFN-free regimens translated in a substantial change of the therapeutic scenario of thalassemia care with the prospect of a significant improvement of the natural course of this complex disease and hopefully of patient survival, too. ${ }^{99}$

\section{Conclusion}

The implementation of screening for HCV of donors and the manufacture of virus-free concentrates of clotting factors have progressively led to the interruption of HCV transmission to patients with IBD, making this infection a more than a rare event in the care of IBD. More recently, the advent of IFNfree regimens based on DAA made treatment of hepatitis $C$ possible in every infected patient, including those who were considered hard to cure with IFN. Thanks to these achievements, a generation of young, HCV-free patients with IBD is cumulating everywhere in the world that represents a first stone in the building of a firewall against dissemination of $\mathrm{HCV}$, a first step for the implementation of the ambitious 
program of World Health Organization (WHO) aiming at the elimination of viral hepatitis. ${ }^{100}$

\section{Main Concepts and Learning Points}

- Chronic infection with the hepatitis C virus (HCV) has long been the dominant complication of substitution therapy in patients with inherited blood disorders (IBD) and the cause of anticipated death due to end-stage liver disease.

- Transmission of hepatitis $\mathrm{C}$ with clotting factors concentrates was halted in the mid-1980s following the adoption of procedures of virus inactivation of concentrates, whereas in the early 1980s transfusion-transmitted hepatitis was interrupted following the widespread adoption of $\mathrm{HCV}$ screening of blood donors.

- The advent of direct antiviral agents (DAAs) has revolutionized therapy of HCV providing substantial clinical benefits including prevention of liver-related mortality and making elimination of hepatitis $C$ in IBD patients, possible.

- The process leading to the identification of HCV as a dominant cause of liver disease in hemophilia and the approaches that allowed the transmission of HCV to IBD populations to be halted.

- DAA treatment of hepatitis $C$ as part of a microelimination program targeting IBD is an effective intervention aiming to prevent transmission of HCV to the general population.

\section{Conflicts of Interest}

M. Colombo is a consultant for Merck, Roche, Novartis, Bayer, BMS, Gilead Sciences, Tibotec, Vertex, Janssen Cilag, Achillion, Lundbeck, GSK, GenSpera, AbbVie, Alfa Wasserman, and Intercept; M.G. Rumi is a consultant for AbbVie, Gilead Sciences, and Merck; V. Di Marco is a consultant for AbbVie,Gilead Science, Merck, and BMS.

\section{References}

1 Rumi MG, Colombo M, Gringeri A, Mannucci PM. High prevalence of antibody to hepatitis $C$ virus in multitransfused hemophiliacs with normal transaminase levels. Ann Intern Med 1990; 112(05):379-380

2 Makris M, Preston FE, Triger DR, et al. Hepatitis C antibody and chronic liver disease in haemophilia. Lancet 1990;335 (8698):1117-1119

3 Mannucci PM, Ronchi G, Rota L, Colombo M. Liver biopsy in hemophilia. Ann Intern Med 1978;88(03):429-430

4 Colombo M, Rumi MG. Liver disease and pathology in hemophilia. Scand J Haematol Suppl 1984;40:341-348

5 Theodore D, Fried MW, Kleiner DE, et al. Liver biopsy in patients with inherited disorders of coagulation and chronic hepatitis $C$. Haemophilia 2004;10(05):413-421

6 Cunningham MJ, Macklin EA, Neufeld EJ, Cohen AR; Thalassemia Clinical Research Network. Complications of beta-thalassemia major in North America. Blood 2004;104(01):34-39

7 Posthouwer D, Makris M, Yee TT, et al. Progression to end-stage liver disease in patients with inherited bleeding disorders and hepatitis C: an international, multicenter cohort study. Blood 2007;109(09):3667-3671
8 Orman ES, Fried MW. Hepatitis C viral infection in patients with hemophilia and hemolytic disorders. Clin Liver Dis 2012;1:95-97

9 Di Marco V, Capra M, Angelucci E, et al; Italian Society for the Study of Thalassemia and Haemoglobinopathies; Italian Association for the Study of the Liver. Management of chronic viral hepatitis in patients with thalassemia: recommendations from an international panel. Blood 2010;116(16):2875-2883

10 Mannucci PM, Colombo M. Virucidal treatment of clotting factor concentrates. Lancet 1988;2(8614):782-785

11 Mannucci PM, Schimpf K, Brettler DB, et al; International Study Group. Low risk for hepatitis $C$ in hemophiliacs given a highpurity, pasteurized factor VIII concentrate. Ann Intern Med 1990;113(01):27-32

12 Hermans C, Altisent C, Batorova A, et al; European Haemophilia Therapy Standardisation Board. Replacement therapy for invasive procedures in patients with haemophilia: literature review, European survey and recommendations. Haemophilia 2009;15 (03):639-658

13 Franchini M, Nicolini N, Capra F. Treatment of hepatitis C in hemophiliacs. Am J Hematol 2006;81(09):696-702

14 Posthouwer D, Mauser-Bunschoten EP, Fischer K, Makris M. Treatment of chronic hepatitis $C$ in patients with haemophilia: a review of the literature. Haemophilia 2006;12(05):473-478

15 Tagliaferri A, Rivolta GF, Iorio A, et al; Italian Association of Hemophilia Centers. Mortality and causes of death in Italian persons with haemophilia, 1990-2007. Haemophilia 2010;16 (03):437-446

16 Rumi MG, Colombo M, Romeo R, Colucci G, Gringeri A, Mannucci PM. Serum hepatitis B virus DNA detects cryptic hepatitis B virus infections in multitransfused hemophilic patients. Blood 1990; 75(08):1654-1658

17 Soriano V, Sulkowski M, Bergin C, et al. Care of patients with chronic hepatitis $\mathrm{C}$ and HIV co-infection: recommendations from the HIV-HCV International Panel. AIDS 2002;16(06):813-828

18 Goedert JJ, Eyster ME, Lederman MM, et al. End-stage liver disease in persons with hemophilia and transfusion-associated infections. Blood 2002;100(05):1584-1589

19 Colombo M, Mannucci PM, Brettler DB, et al. Hepatocellular carcinoma in hemophilia. Am J Hematol 1991;37(04):243-246

20 Tradati F, Colombo M, Mannucci PM, et al; The Study Group of the Association of Italian Hemophilia Centers. A prospective multicenter study of hepatocellular carcinoma in Italian hemophiliacs with chronic hepatitis C. Blood 1998;91(04):1173-1177

21 Santagostino E, Colombo M, Rivi M, et al; Study Group of the Association of Italian Hemophilia Centers. A 6-month versus a 12-month surveillance for hepatocellular carcinoma in 559 hemophiliacs infected with the hepatitis C virus. Blood 2003; 102(01):78-82

22 Ragni MV, Humar A, Stock PG, et al. Hemophilia liver transplantation observational study. Liver Transpl 2017;23(06):762-768

23 Belli LS, Duvoux C, Berenguer M, et al. ELITA consensus statements on the use of DAAs in liver transplant candidates and recipients. J Hepatol 2017;67(03):585-602

24 Colombo M, Mannucci PM, Carnelli V, Savidge GF, Gazengel C, Schimpf $K$. Transmission of non-A, non-B hepatitis by heattreated factor VIII concentrate. Lancet 1985;2(8445):1-4

25 Mannucci PM, Gdovin S, Gringeri A, et al; The Italian Collaborative Group. Transmission of hepatitis A to patients with hemophilia by factor VIII concentrates treated with organic solvent and detergent to inactivate viruses. Ann Intern Med 1994;120(01):1-7

26 Makris M, Preston FE, Triger DR, Underwood JC, Westlake L, Adelman MI. A randomized controlled trial of recombinant interferon- $\alpha$ in chronic hepatitis $C$ in hemophiliacs. Blood 1991;78(07):1672-1677

27 Bresters D, Mauser-Bunschoten EP, Cuypers HT, et al. Long term treatment of chronic hepatitis $C$ with interferon alfa-2b: disappearance of HCV-RNA in a pilot study of eight haemophilia patients. Gut 1993;34(2, Suppl):S124-S125 
28 Peerlinck K, Willems M, Sheng L, et al. Rapid clearance of hepatitis $C$ virus RNA in peripheral blood mononuclear cells of patients with clotting disorders and chronic hepatitis $\mathrm{C}$ treated with alpha-2b interferon is not a predictor for sustained response to treatment. Br J Haematol 1994;86(04):816-819

29 Telfer P, Devereux H, Colvin B, Hayden S, Dusheiko G, Lee C. Alpha interferon for hepatitis $C$ virus infection in haemophilic patients. Haemophilia 1995;1(01):54-58

30 Yoshikawa M, Fukui H, Kojima H, et al. Interferon treatment of chronic hepatitis $\mathrm{C}$ in patients with hemophilia or von Willebrand's disease in Japan. J Gastroenterol 1995;30(03):367-371

31 Yamada M, Fukuda Y, Koyama Y, et al. A long-term follow-up study of interferon treatment for chronic hepatitis $C$ in Japanese patients with congenital bleeding disorders. Eur J Haematol 1996;57(02):165-170

32 Hanley JP, Jarvis LM, Andrew J, et al. Interferon treatment for chronic hepatitis $C$ infection in hemophiliacs-influence of virus load, genotype, and liver pathology on response. Blood 1996;87 (05):1704-1709

33 Rumi MG, Santagostino E, Morfini M, et al; Hepatitis Study Group of the Association of Italian Hemophilia Centers. A multicenter controlled, randomized, open trial of interferon $\alpha 2 b$ treatment of anti-human immunodeficiency virus-negative hemophilic patients with chronic hepatitis C. Blood 1997;89(10):3529-3533

34 Pinilla J, Quintana M, Magallon M. High-dose and long-term therapy of $\alpha$ interferon in hemophiliac patients with chronic $C$ virus hepatitis. Blood 1998;91(02):727-728

35 Laursen AL, Scheibel E, Ingerslev J, et al. Alpha interferon therapy in Danish haemophiliac patients with chronic hepatitis C: results of a randomized controlled open label study comparing two different maintenance regimens following standard interferonalpha-2b treatment. Haemophilia 1998;4(01):25-32

36 Adamowicz-Salach A, Pawelec K, Loch T, et al. Incidence and treatment of hepatitis $C$ virus infection in children with haemophilia in Poland. Haemophilia 1999;5(06):436-440

37 Hayashi K, Fukuda Y, Nakano I, et al. Poor response to interferon treatment for chronic hepatitis $C$ in human immunodeficiency virus-infected haemophiliacs. Haemophilia 2000;6(06):677-681

38 Beurton I, Bertrand MA, Bresson-Hadni S, et al. Interferon alpha therapy in haemophilic patients with chronic hepatitis C: a French multicentre pilot study of 58 patients. Eur J Gastroenterol Hepatol 2001;13(07):859-864

39 Hanabusa H. Efficacy of induction therapy with high-dose interferon for patients with hemophilia and human immunodeficiency virus-hepatitis C virus coinfection. Clin Infect Dis 2002; 35(12):1527-1533

40 Shields PL, Mutimer DJ, Muir D, et al. Combined alpha interferon and ribavirin for the treatment of hepatitis $C$ in patients with hereditary bleeding disorders. Br J Haematol 2000;108(02): 254-258

41 Sauleda S, Esteban JI, Altisent C, Puig L, Esteban R, Guardia J. Treatment with interferon plus ribavirin in anti-HIV negative patients with congenital coagulation disorders and chronic hepatitis C. Thromb Haemost 2000;83(06):807-810

42 Fried MW, Peter J, Hoots K, et al. Hepatitis C in adults and adolescents with hemophilia: a randomized, controlled trial of interferon alfa-2b and ribavirin. Hepatology 2002;36(4 Pt 1):967-972

43 Santagostino E, De Filippi F, Rumi MG, Rivi M, Colombo M, Mannucci PM; Hepatitis Study Group of the Association of Italian Hemophilia Centers. Sustained suppression of hepatitis $C$ virus by high doses of interferon and ribavirin in adult hemophilic patients. Transfusion 2004;44(05):790-794

44 Santagostino E, Rumi MG, Rivi M, Colombo M, Mannucci PM; Hepatitis Study Group of the Association of Italian Hemophilia Centers. Sustained suppression of hepatitis $C$ virus by interferon and ribavirin in hemophilic patients not responding to interferon monotherapy. Blood 2002;99(03):1089-1091
45 Franchini M, Tagliaferri A, Rossetti G, et al. Interferon and ribavirin in HIV-negative haemophiliacs with chronic hepatitis C who were nonresponders to a previous interferon treatment. Haemophilia 2002;8(06):794-797

46 Mancuso ME, Santagostino E, Linari S, et al. Sustained suppression of hepatitis $C$ by pegylated interferon (pegIFN) and ribavirin in hemophilic patients. Haemophilia 2004;10:S48

47 Theodossiades G, Nomikou E, Tsevrenis V, et al. Treatment with peg-interferon alpha- $2 b$ and ribavirin in patients with congenital hemorrhagic disorders and HCV infection. Haemophilia 2004; $10:$ S50

48 Posthouwer D, Yee TT, Makris M, et al. Antiviral therapy for chronic hepatitis $C$ in patients with inherited bleeding disorders: an international, multicenter cohort study. J Thromb Haemost 2007;5(08):1624-1629

49 Pérez-Olmeda M, Núñez M, Romero M, et al. Pegylated IFN- $\alpha 2 b$ plus ribavirin as therapy for chronic hepatitis C in HIV-infected patients. AIDS 2003;17(07):1023-1028

50 Sulkowski MS. Viral hepatitis and HIV coinfection. J Hepatol 2008;48(02):353-367

51 Alberti A, Clumeck N, Collins S, et al; ECC Jury. Short statement of the first European Consensus Conference on the treatment of chronic hepatitis B and C in HIV co-infected patients. J Hepatol 2005;42(05):615-624

52 Makris M, Konkle BA. Hepatitis C in haemophilia: time for treatment for all. Haemophilia 2017;23(02):180-181

53 Younossi ZM, Singer ME, Mir HM, Henry L, Hunt S. Impact of interferon free regimens on clinical and cost outcomes for chronic hepatitis C genotype 1 patients. J Hepatol 2014;60(03):530-537

54 Ackens R, Posthouwer D. Treatment of chronic hepatitis C with direct acting antiviral agents in patients with haemophilia, endstage liver disease and coinfected with HIV. Haemophilia 2016; 22(03):e223-e225

55 Walsh CE, Workowski K, Terrault NA, et al. Ledipasvir-sofosbuvir and sofosbuvir plus ribavirin in patients with chronic hepatitis $C$ and bleeding disorders. Haemophilia 2017;23(02):198-206

56 Nagao A, Hanabusa H. Brief report: the impact of ledipasvir/ sofosbuvir on HIV-positive and HIV-negative Japanese hemophilia patients with 1,4 , and mixed-genotype HCV. J Acquir Immune Defic Syndr 2017;74(04):418-422

57 Stedman CAM, Hyland RH, Ding X, Pang PS, McHutchison JG, Gane EJ. Once daily ledipasvir/sofosbuvir fixed-dose combination with ribavirin in patients with inherited bleeding disorders and hepatitis C genotype 1 infection. Haemophilia 2015; 22:214-217

58 Lee HW, Yoo KY, Won JW, Kim HJ. Direct acting antiviral agents in Korean patients with chronic hepatitis $C$ and hemophilia who are treatment-naïve or treatment-experienced. Gut Liver 2017; 11(05):721-727

59 Hézode C, Colombo M, Bourlière M, et al; C-EDGE IBLD Study Investigators. Elbasvir/grazoprevir for patients with hepatitis $C$ virus infection and inherited blood disorders: a phase III study. Hepatology 2017;66(03):736-745

60 European Association for the Study of the Liver. Electronic address: easloffice@easloffice.eu. EASL Recommendations on Treatment of Hepatitis C 2016. J Hepatol 2017;66(01):153-164

61 Bourlière M, Gordon SC, Flamm SL, et al; POLARIS-1 and POLARIS-4 Investigators. Sofosbuvir, velpatasvir, and voxilaprevir for previously treated HCV infection. N Engl J Med 2017;376 (22):2134-2146

62 Zeuzem S, Foster GR, Wang S, et al. Glecaprevir-pibrentasvir for 8 or 12 weeks in HCV genotype 1 or 3 infection. N Engl J Med 2018; 378(04):354-369

63 Olivieri NF, Nathan DG, MacMillan JH, et al. Survival in medically treated patients with homozygous beta-thalassemia. N Engl J Med 1994;331(09):574-578

64 Borgna-Pignatti C, Rugolotto S, De Stefano P, et al. Survival and complications in patients with thalassemia major treated with 
transfusion and deferoxamine. Haematologica 2004;89(10): 1187-1193

65 Olivieri NF, Brittenham GM, Matsui D, et al. Iron-chelation therapy with oral deferiprone in patients with thalassemia major. N Engl J Med 1995;332(14):918-922

66 Cappellini MD, Cohen A, Piga A, et al. A phase 3 study of deferasirox (ICL670), a once-daily oral iron chelator, in patients with beta-thalassemia. Blood 2006;107(09):3455-3462

67 Laperche S. Blood safety and nucleic acid testing in Europe. Euro Surveill 2005;10(02):3-4

68 Prati D. Transmission of hepatitis $C$ virus by blood transfusions and other medical procedures: a global review. J Hepatol 2006; 45(04):607-616

69 Prati D, Zanella A, Farma E, et al. A multicenter prospective study on the risk of acquiring liver disease in anti-hepatitis $C$ virus negative patients affected from homozygous beta-thalassemia. Blood 1998;92(09):3460-3464

70 Jang TY, Lin PC, Huang CI, et al. Seroprevalence and clinical characteristics of viral hepatitis in transfusion-dependent thalassemia and hemophilia patients. PLoS One 2017;12(06):e0178883

71 Ahmed Kiani R, Anwar M, Waheed U, Asad MJ, Abbasi S, Abbas Zaheer $\mathrm{H}$. Epidemiology of transfusion transmitted infection among patients with $\beta$-thalassaemia major in Pakistan. J Blood Transfus 2016;2016:8135649

72 Jafroodi M, Davoudi-Kiakalayeh A, Mohtasham-Amiri Z, Pourfathollah AA, Haghbin A. Trend in prevalence of hepatitis $C$ virus infection among $\beta$-thalassemia major patients: 10 years of experience in Iran. Int J Prev Med 2015;6:89. Doi: 10.4103/ 2008-7802.164832

73 Al-Naamani K, Al-Zakwani I, Al-Sinani S, Wasim F, Daar S. Prevalence of hepatitis $C$ among multi-transfused thalassaemic patients in Oman: single centre experience. Sultan Qaboos Univ Med J 2015;15(01):e46-e51

74 Chakrabarty P, Rudra S, Hossain MA. Prevalence of HBV and HCV among the multi-transfused beta thalassemic major patients in a day care centre of blood transfusion department of Mymensingh Medical College Hospital. Mymensingh Med J 2014;23(02): 235-241

75 Hussein E. Evaluation of infectious disease markers in multitransfused Egyptian children with thalassemia. Ann Clin Lab Sci 2014;44(01):62-66

76 Mansour AK, Aly RM, Abdelrazek SY, et al. Prevalence of HBV and HCV infection among multi-transfused Egyptian thalassemic patients. Hematol Oncol Stem Cell Ther 2012;5(01):54-59

77 Al-Sweedan SA, Jaradat S, Amer K, Hayajneh W, Haddad H. Seroprevalence and genotyping of hepatitis $C$ virus in multiple transfused Jordanian patients withß-thalassemia major. Turk J Haematol 2011;28(01):47-51

78 Di Marco V, Bronte F, Calvaruso V, et al. IL28B polymorphisms influence stage of fibrosis and spontaneous or interferoninduced viral clearance in thalassemia patients with hepatitis C virus infection. Haematologica 2012;97(05):679-686

79 Borgna-Pignatti C, Cappellini MD, De Stefano P, et al. Cardiac morbidity and mortality in deferoxamine- or deferiprone-treated patients with thalassemia major. Blood 2006;107(09):3733-3737

80 Pennell DJ, Porter JB, Cappellini MD, et al. Efficacy of deferasirox in reducing and preventing cardiac iron overload in beta-thalassemia. Blood 2010;115(12):2364-2371

81 Di Marco V, Capra M, Gagliardotto F, et al. Liver disease in chelated transfusion-dependent thalassemics: the role of iron overload and chronic hepatitis C. Haematologica 2008;93(08): 1243-1246

82 Singh S, Muir AJ, Dieterich DT, Falck-Ytter YT. American Gastroenterological Association Institute technical review on the role of elastography in chronic liver diseases. Gastroenterology 2017; 152(06):1544-1577
83 Di Marco V, Bronte F, Cabibi D, et al. Noninvasive assessment of liver fibrosis in thalassaemia major patients by transient elastography (TE) - lack of interference by iron deposition. $\mathrm{Br} J$ Haematol 2010;148(03):476-479

84 Fraquelli M, Cassinerio E, Roghi A, et al. Transient elastography in the assessment of liver fibrosis in adult thalassemia patients. Am J Hematol 2010;85(08):564-568

85 Sarigianni M, Liakos A, Vlachaki E, et al. Accuracy of magnetic resonance imaging in diagnosis of liver iron overload: a systematic review and meta-analysis. Clin Gastroenterol Hepatol 2015;13(01):55-63.e5

86 Angelucci E, Muretto P, Nicolucci A, et al. Effects of iron overload and hepatitis $C$ virus positivity in determining progression of liver fibrosis in thalassemia following bone marrow transplantation. Blood 2002;100(01):17-21

87 Perifanis V, Tziomalos K, Tsatra I, Karyda S, Patsiaoura K, Athanassiou-Metaxa M. Prevalence and severity of liver disease in patients with $\mathrm{b}$ thalassemia major. A single-institution fifteenyear experience. Haematologica 2005;90(08):1136-1138

88 Simonetti RG, Cammà C, Fiorello F, et al. Hepatitis C virus infection as a risk factor for hepatocellular carcinoma in patients with cirrhosis. A case-control study. Ann Intern Med 1992;116 (02):97-102

89 Borgna-Pignatti C, Vergine G, Lombardo T, et al. Hepatocellular carcinoma in the thalassaemia syndromes. Br J Haematol 2004; 124(01):114-117

90 Mancuso A, Sciarrino E, Renda MC, Maggio A. A prospective study of hepatocellular carcinoma incidence in thalassemia. Hemoglobin 2006;30(01):119-124

91 Borgna-Pignatti C, Garani MC, Forni GL, et al. Hepatocellular carcinoma in thalassaemia: an update of the Italian Registry. $\mathrm{Br} \mathrm{J}$ Haematol 2014;167(01):121-126

92 Di Marco V, Lo Iacono O, Almasio P, et al. Long-term efficacy of alpha-interferon in beta-thalassemics with chronic hepatitis $C$. Blood 1997;90(06):2207-2212

93 Di Marco V, D'Ambrosio R, Bronte F, et al; on behalf ITHACA (Italy for THAalassemia, hepatitis C Advances) Group. Dual therapy with peg-interferon and ribavirin in thalassemia major patients with chronic HCV infection: is there still an indication? Dig Liver Dis 2016;48(06):650-655

94 Sinakos E, Kountouras D, Koskinas J, et al. Treatment of chronic hepatitis $C$ with direct-acting antivirals in patients with $\beta$ thalassaemia major and advanced liver disease. $\mathrm{Br} \mathrm{J}$ Haematol 2017;178(01):130-136

95 Mangia A, Sarli R, Gamberini R, et al. Randomised clinical trial: sofosbuvir and ledipasvir in patients with transfusion-dependent thalassaemia and HCV genotype 1 or 4 infection. Aliment Pharmacol Ther 2017;46(04):424-431

96 Origa R, Ponti ML, Filosa A, et al; Italy for THAlassemia and hepatitis C Advance - Società Italiana Talassemie ed Emoglobinopatie (ITHACA-SITE). Treatment of hepatitis C virus infection with direct-acting antiviral drugs is safe and effective in patients with hemoglobinopathies. Am J Hematol 2017;92(12):1349-1355

97 Nagral A, Sawant S, Nagral N, Parikh P, Malde P, Merchant R. Generic direct acting antivirals in treatment of chronic hepatitis $\mathrm{C}$ infection in patients of thalassemia major. J Clin Exp Hepatol 2017;7(03):172-178

98 Hill A, Khwairakpam G, Wang J, et al. High sustained virological response rates using imported generic direct acting antiviral treatment for hepatitis C. J Virus Erad 2017;3(04):200-203

99 D'Ambrosio R, Lampertico P. Editorial: good news to patients with thalassaemia-HCV clearance made easy with direct-acting antivirals. Aliment Pharmacol Ther 2017;46(06):628-629

100 Lazarus JV, Wiktor S, Colombo M, Thursz M; EASL International Liver Foundation. Micro-elimination - a path to global elimination of hepatitis C. J Hepatol 2017;67(04):665-666 